\title{
Re: Comments on "Pure or Complex Hereditary Spastic Paraplegia Type 4?": The Authors Respond
}

\author{
Jiwon Yang ${ }^{a}$ \\ Ja Young Seo ${ }^{\mathrm{b}}$ \\ Kwang-Woo Lee ${ }^{a}$ \\ Hyeon-Mi Park ${ }^{\mathrm{a}}$ \\ aDepartments of Neurology and \\ 'Laboratory Medicine, Gil Medical Center, \\ Gachon University College of Medicine, \\ Incheon, Korea
}

Received November 28, 2018

Revised December 2, 2018

Accepted December 5, 2018

\section{Correspondence}

Hyeon-Mi Park, MD, PhD

Department of Neurology,

Gil Medical Center, Gachon University

College of Medicine

21 Namdong-daero,

774beon-gil, Namdong-gu,

Incheon 21565, Korea

Tel +82-32-460-3346

Fax +82-32-460-3344

E-mail neurohm@gilhospital.com
Dear Editor,

We thank J. Finsterer for his interest in and comments on our article. He was interested in the clinical symptoms of the patient, who presented with lower limb spasticity without muscle weakness. Finsterer was concerned about whether the reported patient developed any additional neurological signs during the follow-up period. The patient visited our clinic monthly for 5 months, during which he did not report new symptoms and neurological examinations did not revealed any interval changes. Unfortunately, thereafter the patient moved to an area more than $330 \mathrm{~km}$ from our clinic, and so we could not follow him further. Although he showed spastic gait, pathologically increased muscle stretch reflexes in the knees and ankles, and positive Babinski signs with ankle clonus, he could walk independently and did not exhibit muscle weakness or a diminished vibration sensation in the feet. He denied any urinary difficulties. Since clinical symptoms vary according to the age at onset and disease duration, ${ }^{1}$ and the age at onset was 42 years with a disease duration of approximately 3 years in our patient, there is a chance that he will deteriorate. However, we consider it unlikely that he will present with the complex form of hereditary spastic paraplegia (HSP) 4, because his mother who carried the same mutation showed almost the same phenotype as him with the exception of mild lower limb weakness. She also could walk unaided. Her disease duration was more than 10 years, although she could not remember the exact age at onset. Therefore, we expect our patient and his mother to be a pure type of HSP. He did not need therapeutic interventions at the time of diagnosis, and recommended that he receive regular physiotherapy.

We thank J. Finsterer for his comments about the number of known HSP genes identified to date (79 loci and 65 genes). ${ }^{2,3}$

Conflicts of Interest

The authors have no potential conflicts of interest to disclose.

\section{REFERENCES}

1. Harding AE. Hereditary "pure" spastic paraplegia: a clinical and genetic study of 22 families. J Neurol Neurosurg Psychiatry 1981;44:871-883.

2. Koh K, Ishiura H, Tsuji S, Takiyama Y. JASPAC: Japan Spastic Paraplegia Research Consortium. Brain Sci 2018;8:153.

3. Parodi L, Coarelli G, Stevanin G, Brice A, Durr A. Hereditary ataxias and paraparesias: clinical and genetic update. Curr Opin Neurol 2018;31:462-471.
@ This is an Open Access article distributed under the terms of the Creative Commons Attribution Non-Commercial License (https://creativecommons.org/licenses/by-nc/4.0) which permits unrestricted non-commercial use, distribution, and reproduction in any medium, provided the original work is properly cited. 